\title{
Once an island, now the focus of attention
}

\author{
A. D. Craig
}

Published online: 29 May 2010

(C) Springer-Verlag 2010

The insula (originally called the "island of Reil") is emerging from its hiding place inside of the human brain. It is easy to find articles and textbooks which show the lateral aspect of the brain but barely mention the insula, if at all (http://www.ninds.nih.gov/disorders/brain_basics/ know_your_brain.htm) or treat it as a deep brain structure, like the amygdala (http://www.scientificamerican.com/ article.cfm?id=faulty-circuits). In fact, in Brodmann's famous map of cortical cytoarchitectonic areas, it was not even worthy of a number! [See Kurth et al. 2009, PMID: 19822572; Brodmann (1909) described only a posterior granular and an anterior agranular region in the human insular cortex.] Older neuroscientists remember the insula as a portion of the visceral brain, based on prominent writings by Penfield, Mesulam, Saper, and others (Penfield and Faulk 1955; Mesulam and Mufson 1982; Saper 2002); some investigators simply call it a multi-modal region and cite the brief reviews by Augustine (1985, 1996); but for many new investigators who find it unexpectedly activated in their functional imaging study, it is simply an enigma.

I came upon the insula by following a neural pathway for pain and temperature using functional anatomical methods (Craig et al. 1994). Eventually, I realized that the cortical terminus of this pathway in the posterior insula of primates provides a homeostatic representation of the physiological condition of the body (Craig 2002). When my collaborators and I performed an imaging study designed to document this interoceptive pathway in humans, we found that an extension of this pathway to the anterior insula correlated with subjective feelings from the body, consonant with the well-known predictions of the James-Lange theory of

A. D. Craig $(\varangle)$

Barrow Neurological Institute, Phoenix, AZ, USA

e-mail: Bud.Craig@CHW.edu emotion and the "somatic marker" hypothesis (Craig et al. 2000). At that time, functional imaging was still emerging, and few studies had observed insular activation. Today, a PubMed search for "insula AND imaging" limited to English and Humans pulls up 30,415 references!

In order to provide an overview of this vast literature for a 2009 opinion article (Craig 2009), I compiled reports from disparate and unfamiliar branches of neuroscience. To my mind, this burgeoning literature compelled the hypothesis that the anterior insula engenders human awareness, yet only one article had directly addressed this possibility (Klein et al. 2007), and an astonishing number of authors had reported strong activation of the insula without comment. The immediate need for an anthology became obvious, in which leading primary investigators from these disparate fields could re-appraise the role of the insula in light of the new perspective provided by this extraordinary convergence of evidence. I shared this idea with Antoine Bechara, Hugo Critchley, and Steve Petersen, who graciously agreed to serve as Co-Editors. We elected to generate a Special Issue in a leading journal, to enable rapid on-line publication and broad accessibility. Our excitement was validated when every investigator queried agreed to contribute to this Special Issue on the insula.

The first six articles of this set are contributed by clinical investigators, and while each focuses on particular aspects of human behavior, each one also emphasizes the multiplicity of functions attributable to the insula (Ibañez et al. 2010; Karnath and Baier 2010; Ackermann and Riecker 2010; Naqvi and Bechara 2010; Paulus and Stein 2010; Seeley 2010). The next three articles address neuroanatomical issues that are significant for our appreciation of how special the human insula really is, and these articles underscore fertile opportunities for neurogenetic and functional analyses (Butti and Hof 2010; Allman et al. 2010; Kurth et al. 
2010). The next five articles provide convergent views on the role of the human insula in affective feelings from the body and subjective emotional feelings, and each one presents novel insights on the functional organization of the human insula (Medford and Critchley 2010; Small 2010; Craig 2010; Lamm and Singer 2010; Garavan 2010). The final seven articles present a range of various perspectives on what are undoubtedly the most surprising new findings on the central role of the anterior insula in human perception, cognition, performance, and attention (Brass and Haggard 2010; Sterzer and Kleinschmidt 2010; Kosillo and Smith 2010; Ullsperger et al. 2010; Bossaerts 2010; Menon and Uddin 2010; Nelson et al. 2010).

The overall goal of this set of articles is to provide a solid starting point for new investigators by identifying the issues and the opportunities for advances in our knowledge of this unique portion of the human brain. The authors were encouraged by the peer reviewers and the editors to be thorough and prospective, and to express their individual viewpoint as lucidly as possible. We hope that young neuroscientists will find fertile ground here. Indeed, we are all excited by the prospects for awe-inspiring discoveries in the convergence of these disparate fields of neuroscience.

My Co-Editors and I are deeply grateful to all of these authors for sharing their views and their time. We are also grateful to the journal Brain Structure and Function for this special opportunity, to Co-Editors-in-Chief Laszlo Zaborszky and Karl Zilles for their constant encouragement and guidance, and to Andrea Pillmann, Neil Solomon, Thomas Tschech and Revathy Ramalingam for operational support. We all hope that this Special Issue on the insula will serve as a primary resource for years to come.

\section{References}

Ackermann H, Riecker A (2010) The contribution(s) of the insula to speech communication: a review of the clinical and functional imaging literature. Brain Struc Func 214(5-6). doi:10.1007/ s00429-010-0257-x

Allman JM, Tetreault NA, Hakeem AY, Manaye KF, Semendeferi K, Erwin JM, Park S, Goubert V, Hof PR (2010) The von Economo neurons in frontoinsular and anterior cingulate cortex in great apes and humans. Brain Struc Func 214(5-6). doi:10.1007/ s00429-010-0254-0

Augustine JR (1985) The insular lobe in primates including humans. Neurol Res 7:2-10

Augustine JR (1996) Circuitry and functional aspects of the insular lobe in primates including humans. Brain Res Rev 22:229-244

Bossaerts P (2010) Risk and risk prediction error signals in anterior insula. Brain Struc Func 214(5-6). doi:10.1007/s00429-0100253-1

Brass M, Haggard P (2010) The hidden side of intentional action: the role of the anterior insular cortex. Brain Struc Func 214(5-6). doi:10.1007/s00429-010-0269-6

Butti C, Hof PR (2010) The insular cortex: a comparative perspective. Brain Struc Func 214(5-6). doi:10.1007/s00429-010-0264-y
Craig AD (2002) How do you feel? Interoception: the sense of the physiological condition of the body. Nat Rev Neurosci 3:655-666

Craig AD (2009) How do you feel-now? The anterior insula and human awareness. Nat Rev Neurosci 10:59-70

Craig AD (2010) The sentient self. Brain Struc Func 214(5-6). doi: 10.1007/s00429-010-0248-y

Craig AD, Bushnell MC, Zhang E-T, Blomqvist A (1994) A thalamic nucleus specific for pain and temperature sensation. Nature 372:770-773

Craig AD, Chen K, Bandy D, Reiman EM (2000) Thermosensory activation of insular cortex. Nat Neurosci 3:184-190

Garavan H (2010) The insula and drug cravings. Brain Struc Func 214(5-6). doi:10.1007/s00429-010-0259-8

Ibañez A, Gleichgerrcht E, Manes F (2010) Clinical effects of insular damage in humans. Brain Struc Func 214(5-6). doi:10.1007/ s00429-010-0256-y

Karnath HO, Baier B (2010) Right insula for our sense of limb ownership and self-awareness of actions. Brain Struc Func 214(5-6). doi:10.1007/s00429-010-0250-4

Klein TA, Endrass T, Kathmann N, Neumann J, von Cramon DY, Ullsperger M (2007) Neural correlates of error awareness. Neuroimage 34:1774-1781

Kosillo P, Smith AT (2010) The role of the human anterior insular cortex in time processing. Brain Struc Func 214(5-6). doi: 10.1007/s00429-010-0267-8

Kurth F, Zilles K, Fox PT, Laird AR, Eickhoff SB (2010) A link between the systems: functional differentiation and integration within the human insula revealed by meta-analysis. Brain Struc Func 214(5-6). doi:10.1007/s00429-010-0255-z

Lamm C, Singer T (2010) The role of anterior insular cortex in social emotions. Brain Struc Func 214(5-6). doi:10.1007/s00429010-0251-3

Medford N, Critchley HD (2010) Conjoint activity of anterior insular and anterior cingulate cortex: awareness and response. Brain Struc Func 214(5-6). doi:10.1007/s00429-010-0265-x

Menon V, Uddin LQ (2010) Saliency, switching, attention and control: a network model of insula function. Brain Struc Func 214(5-6). doi:10.1007/s00429-010-0262-0

Mesulam MM, Mufson EJ (1982) Insula of the old world monkey. I. Architectonics in the insulo-orbito-temporal component of the paralimbic brain. J Comp Neurol 212:1-22

Naqvi NH, Bechara A (2010) The insula and drug addiction: an interoceptive view of pleasure, urges and decision-making. Brain Struc Func 214(5-6). doi:10.1007/s00429-010-0268-7

Nelson SM, Dosenbach NUF, Cohen AL, Schlaggar BL, Petersen SE (2010) Role of the anterior insula in task-level control and focal attention. Brain Struc Func 214(5-6). doi:10.1007/s00429010-0260-2

Paulus MP, Stein MB (2010) Interoception in anxiety and depression. Brain Struc Func 214(5-6). doi:10.1007/s00429-010-0258-9

Penfield W, Faulk ME Jr (1955) The insula: further observations on its function. Brain 78:445-470

Saper CB (2002) The central autonomic nervous system: conscious visceral perception and autonomic pattern generation. Annu Rev Neurosci 25:433-469

Seeley WW (2010) Anterior insula degeneration in frontotemporal dementia. Brain Struc Func 214(5-6). doi:10.1007/s00429010-0263-Z

Small DM (2010) Taste representation in the human insula. Brain Struc Func 214(5-6). doi:10.1007/s00429-010-0266-9

Sterzer A, Kleinschmidt P (2010) Anterior insula activations in perceptual paradigms - often observed but barely understood. Brain Struc Func 214(5-6). doi:10.1007/s00429-010-0252-2

Ullsperger M, Harsay HA, Wessel JR, Ridderinkhof KR (2010) Conscious perception of errors and its relation to the anterior insula. Brain Struc Func 214(5-6). doi:10.1007/s00429-010-0261-1 